Article

\title{
Relative Contributions of Clouds and Aerosols to Surface Erythemal UV and Global Horizontal Irradiance in Korea
}

\author{
Jaemin Kim ${ }^{1}$, Yun Gon Lee ${ }^{1, * \mathbb{C}}$, Ja-Ho Koo ${ }^{2}$ (D) and Hanlim Lee ${ }^{3}$ \\ 1 Department of Atmospheric Sciences, Chungnam National University, Daejeon 34134, Korea; \\ jaemin2984@gmail.com \\ 2 Department of Atmospheric Sciences, Yonsei University, Seoul 03722, Korea; zach45@yonsei.ac.kr \\ 3 Division of Earth Environmental System Science Major of Spatial Information Engineering, \\ Pukyong National University, Busan 48513, Korea; hllee@pknu.ac.kr \\ * Correspondence: yglee2@cnu.ac.kr; Tel.: +82-42-821-7101
}

Received: 8 February 2020; Accepted: 19 March 2020; Published: 22 March 2020

\begin{abstract}
The attenuating effects of clouds and aerosols on global horizontal irradiance (GHI) and ultraviolet erythemal irradiance (UVER) were evaluated and compared using data from four sites in South Korea (Gangneung, Pohang, Mokpo, and Gosan) for the period 2005-2016. It was found that GHI and UVER are affected differently by various attenuating factors, resulting in an increase in the ratio of UVER to GHI with a decrease in the clearness index of GHI. A comparative analysis of the clearness indices of GHI and UVER identified an almost linear relationship between two transmittances by applying UVER with fixed slant ozone $\left(\mathrm{UVER}_{300}\right)$ and there was a latitudinal difference in the relationship. Some nonlinearity remained in this relationship, which suggests a contribution by other factors such as clouds and aerosols. Variations of the UVER 300 ratio to GHI with cloud cover and aerosol optical depth were analyzed. The ratio increased with cloud cover and decreased with aerosol optical depth, indicating that clouds attenuate GHI more efficiently than UVER and that the attenuation by aerosols is greater for UVER than for GHI. A multiple linear regression analysis of the clearness indices of GHI and UVER 300 quantitively demonstrates differences in the radiation-reducing effects of clouds and aerosols, with some regional differences by site that can be attributed to local climatic characteristics in South Korea.
\end{abstract}

Keywords: solar irradiance; ultraviolet erythemal irradiance; clearness index; attenuating factors; individual contribution

\section{Introduction}

Energy from solar radiation sustains Earth's ecosystems and climate. The total solar radiation that reaches the Earth's surface is defined as global horizontal irradiance (GHI; 290-2800 nm) and is typically divided into ultraviolet, visible, and infrared radiation by wavelength. Ultraviolet radiation (UV; $100-400 \mathrm{~nm}$ ) can have damaging effects on the human body and ecosystems, and thus careful monitoring of UV is needed. Ultraviolet radiation can be further divided into three sub-classes by wavelength, with 280-320 nm corresponding to ultraviolet B radiation (UV-B; 280-320 nm) [1].

Although $>90 \%$ of UV-B is absorbed by stratospheric ozone, enough radiation reaches the Earth's surface to cause erythema in human skin. MacKinlay and Diffey [2] developed an erythemal action spectrum based on the biological risk of erythema by wavelength. UV erythemal irradiance (UVER) is calculated by weighting this action spectrum to spectral UV-B irradiance, and can be used as an indicator of erythemal risk. However, UV-B also positively affects human health by triggering the synthesis of vitamin-D in human skin [3]. Considering both the negative and positive effects of 
UV radiation, monitoring and routinely informing the public of biologically effective UV irradiance is critical.

However, monitoring UV irradiance requires more expensive equipment than does the monitoring of GHI and also requires periodic quality checks. These limitations have led to fewer UV monitoring stations compared with those for GHI. Thus, researchers often attempt to estimate UV based on global solar radiation observations using a predetermined relationship between UV and GHI with attenuating factors for UV [4-6], UV-B [7,8], and UVER [9-11]. That is, the characteristics of various attenuating factors and their effect on ultraviolet and global solar radiation must be analyzed before estimating UV irradiance. For example, Anton et al. [12] investigated differences in the effects of ozone, clouds, and aerosols on GHI and UVER using the ratio of UVER to GHI in Spain, and they also developed an empirical model for estimating the transmittance of UVER from GHI [9]. They reported that clouds have a higher attenuation effect on GHI than on UVER and that aerosol load also behaves differently in atmospheric transmission of GHI and UVER. Adam [13] investigated the relationship between UV-B and GHI by comparing temporal variation and analyzing the response of the ratio of UV-B and broadband solar radiation to ozone, aerosols and water vapor in Qena, Egypt, before developing a UV-B estimating model in further study [8]. Also, Buntoung et al. [10] estimated UVER based on a sensitivity analysis of UVER and GHI to meteorological factors (solar zenith angle, ozone, aerosols and clearness index) in all- and cloudy-sky conditions in Thailand.

The relationship between UV and GHI is modulated by clouds, aerosols, ozone, and solar zenith angle, which have wavelength-dependent effects on solar irradiance. Generally, the reduction of solar irradiance by clouds is greater at longer wavelengths [14-18] and aerosol attenuation is greater at shorter wavelengths $[19,20]$. Here, we analyze the relative difference in the effects of attenuating factors (clouds and aerosols) on GHI and UVER using ground-based observational irradiance data for the period 2005-2016 at four locations in South Korea to understand the characteristics of GHI and UVER transmittance, and prepare for the development of an UVER model for this region. The effect of clouds and aerosols were compared using two simple parameters: the clearness index, which indicates the atmospheric transmittance of broadband solar radiation, and the ratio of UVER to GHI. Lee et al. [21,22] investigated the spectral dependence of the effects of clouds, aerosols, and ozone on UVER, total UV, and GHI in South Korea, but their investigation was limited to the capital city, Seoul.

The data and methodology used in this study are introduced in Sections 2.1 and 2.2, respectively. In Section 3.1, the relative difference in the changes of UVER and GHI is established by comparing the monthly variation in GHI and UVER and the UVER/GHI response to the clearness index of GHI. In Section 3.2, the relationship between clearness indices of GHI and UVER are analyzed, and in Section 3.3 we provide a correlation analysis of clearness indices and attenuating factors and differences in the UVER/GHI response to clouds and aerosols. Section 3.4 gives the results of multiple linear regression analyses for clearness indices of GHI and UVER. Finally, Section 4 includes a discussion and summary of this study.

\section{Data and Methods}

We compared attenuating effects of clouds and aerosols in GHI and UVER using various analyses: (1) simple comparison of monthly mean GHI and UVER; (2) the relationship between clearness indices of GHI and UVER; (3) UVER/GHI response to each attenuating factor and clearness indices; and (4) multiple linear regression analysis. In particular, the radiative amplification factor (RAF) of ozone was used for removing ozone attenuating effects. The data and methodology used in these analyses are described in detail below. 


\subsection{Data}

\subsubsection{Irradiance Data}

The analysis was conducted for four sites in Korea: Gangneung ( $37^{\circ} 45^{\prime} \mathrm{N}, 128^{\circ} 53^{\prime} \mathrm{E}$ ), Pohang $\left(36^{\circ} 01^{\prime} \mathrm{N}, 129^{\circ} 22^{\prime} \mathrm{E}\right), \operatorname{Mokpo}\left(34^{\circ} 49^{\prime} \mathrm{N}, 126^{\circ} 22^{\prime} \mathrm{E}\right)$, and Gosan $\left(33^{\circ} 17^{\prime} \mathrm{N}, 126^{\circ} 09^{\prime} \mathrm{E}\right)$, where observational data for both GHI and UVER are available for the 12 years from 2005 to 2016. Observational data are from the Korean Meteorological Administration (KMA). Figure 1 shows the spatial distribution of the analysis sites.

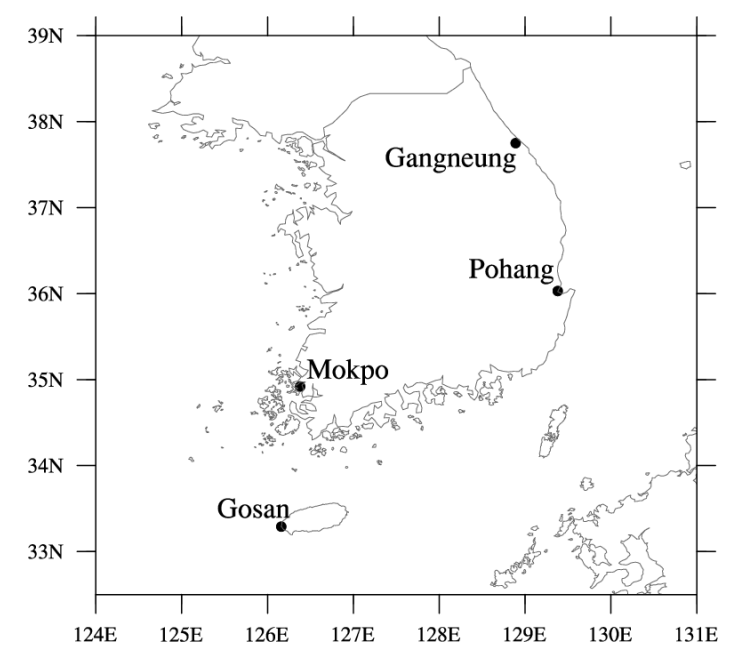

Figure 1. Spatial distribution of analysis sites (Gangneung, Pohang, Mokpo, and Gosan) in South Korea.

Global solar radiation was measured using a pyranometer (CMP-21, Kipp \& Zonen, Netherlands). The CMP-21 pyranometer has non-linearity below $0.2 \%$ in the range of $100-1000 \mathrm{~W} \mathrm{~m}^{-2}$ and a directional response below $10 \mathrm{~W} \mathrm{~m}^{-2}$ (up to $80^{\circ}$ with a $1000 \mathrm{~W} \mathrm{~m}^{-2}$ beam). Spectral error is within $3 \%$ and temperature dependence is below $1 \%$ (from $-20{ }^{\circ} \mathrm{C}$ to $50{ }^{\circ} \mathrm{C}$ ). Irradiance is measured as a $1-\mathrm{min}$ average value using a data logger (CR21X, Campbell Scientific, Logan, UT, USA) and is provided to data users as temporally integrated values. Quality control of the GHI data was performed using methods described by Jung et al. [23]. The measured GHI should be less than top of atmosphere (TOA) irradiance at the same geographical location and larger than the minimum GHI value under continuously overcast conditions.

Erythemal ultraviolet irradiance was observed using a UV-Biometer (Model 501, Solar Light Co., Glenside, PA, USA). The UV-Biometer detects ultraviolet irradiance with a spectral response for erythemal action spectrum with an accuracy of $\pm 5 \%$ for the daily total irradiance. The spectral response is similar to the CIE action spectrum, that is, it is normalized to 1 at below $297 \mathrm{~nm}$, and the logarithm of the normalized spectral response decreases linearly with wavelength being about 0.001 at $330 \mathrm{~nm}$. Calibration of the instrument is initially carried out by the manufacturer to show the biological effectiveness of the solar radiation in a condition of a clear sky, $30^{\circ}$ solar zenith angle and $2.7 \mathrm{~mm}$ ozone column thickness at sea level and a sensor temperature of $25^{\circ} \mathrm{C}$. The sensor is re-calibrated twice per year by comparing it with a reference sensor. The UV-biometer provides integrated ultraviolet radiation for 10-min periods in units of minimum erythemal dose (MED; $1 \mathrm{MED}=210 \mathrm{~J} / \mathrm{m}^{2}$ ) [24]. Erythemal UV measurements that meet the following criteria are excluded from the analysis: (1) device temperature $\neq 25^{\circ} \mathrm{C}$, or (2) values $>0$ after sunset. Daily integrated GHI and UVER values were used in the analysis only if all data are available for the whole day.

Irradiance observations at analysis sites are operated and managed by KMA with periodical dome surface cleaning and normal operation checks. All instruments including pyranometers and biometers are installed in proper locations where there are no obstacles to cause shadows and highly reflective objects around the device. 


\subsubsection{Attenuating Factors}

Clouds, aerosols, and ozone affect the transmittance of radiation to reach the Earth's surface. We used daily average of cloud cover (CC) data observed in units of tenth per hour from KMA weather stations. As there are no readily available aerosol optical depth (AOD) and total ozone column (TOC) measurements for the analysis sites, these two factors are based on reanalysis and remote sensing data, respectively. For AOD, 3-hourly AOD data from the Modern-Era Retrospective analysis for Research and Applications, version 2 (MERRA-2) were used to generate daily averages. For ozone, TOC data were obtained from two remote sensors, the Ozone Monitoring Instrument (OMI) on Aura and the Ozone Mapping and Profiler Suite (OMPS) on Suomi- National Polar-orbiting Partnership (NPP). If a TOC is observed by more than one sensor on one day, the values were averaged before use in the analysis. We converted TOC to slant column density (SCD) using the solar zenith angle (SZA, $\theta$ ) according to Equation (1), which describes the amount of ozone along the solar radiation optical path:

$$
\mathrm{SCD}=\frac{\mathrm{TOC}}{\cos (\theta)}
$$

Previous studies have also used SCD in analyses of the effects of ozone on UV radiation $[12,25,26]$. The spatial resolution of the AOD and SCD data are $0.5^{\circ} \times 0.625^{\circ}$ and $1^{\circ} \times 1^{\circ}$, respectively. The AOD and SCD data were extracted from the grid point closest to the irradiance observations. Table 1 summarizes the annual mean values of the influencing factors at the analysis sites.

Table 1. Summary of geophysical information and annual average values for the attenuating factors (cloud cover (CC), aerosol optical depth (AOD), total ozone column (TOC), and slant column density (SCD)) during the analysis period.

\begin{tabular}{cccccc}
\hline Site & Latitude/Longitude & CC & AOD & TOC & SCD \\
\hline Gangneung & $37^{\circ} 45^{\prime} \mathrm{N}, 128^{\circ} 53^{\prime} \mathrm{E}$ & $5.08( \pm 0.3)$ & $0.26( \pm 0.03)$ & $325( \pm 6.4)$ & $474( \pm 9.6)$ \\
Pohang & $36^{\circ} 01^{\prime} \mathrm{N}, 129^{\circ} 23^{\prime} \mathrm{E}$ & $4.90( \pm 0.2)$ & $0.33( \pm 0.03)$ & $319( \pm 6.2)$ & $452( \pm 9.0)$ \\
Mokpo & $34^{\circ} 49^{\prime} \mathrm{N}, 126^{\circ} 22^{\prime} \mathrm{E}$ & $5.43( \pm 0.2)$ & $0.39( \pm 0.04)$ & $306( \pm 5.8)$ & $418( \pm 8.3)$ \\
Gosan & $33^{\circ} 17^{\prime} \mathrm{N}, 126^{\circ} 10^{\prime} \mathrm{E}$ & $6.12( \pm 0.2)$ & $0.38( \pm 0.03)$ & $300( \pm 5.5)$ & $399( \pm 7.7)$ \\
\hline
\end{tabular}

\subsection{Methods}

\subsubsection{Clearness Index}

The clearness index, the ratio of irradiance at the surface to TOA irradiance, is an indicator of atmospheric transmittance and is calculated as

$$
\text { Clearness index }=\frac{\mathrm{I}}{\mathrm{I}_{0}}
$$

where $\mathrm{I}$ and $\mathrm{I}_{0}$ are the daily cumulative radiation at the surface and the TOA, respectively. The $\mathrm{I}_{0}$ is calculated according to Iqbal [1] as follows:

$$
\mathrm{I}_{0}=\frac{24}{\pi} \mathrm{I}_{\mathrm{sc}} \mathrm{E}_{0}\left[\left(\frac{\pi}{180}\right) \omega_{\mathrm{s}}(\sin \delta \sin \phi)+\left(\cos \delta \cos \phi \sin \omega_{\mathrm{s}}\right)\right] .
$$

In Equation (3), ISC is the solar constant, which is $4921 \mathrm{~kJ} / \mathrm{m}^{2}$ for GHI and $37.08 \mathrm{~kJ} / \mathrm{m}^{2}$ for UVER. The solar constant for UVER is calculated by applying the erythemal weighting function to the solar constant for each wavelength band given by Iqbal [1]. $\mathrm{E}_{0}$ is the eccentricity correction factor for the Earth's orbit, $\phi$ is the latitude of the observation site, $\delta$ is the solar declination, and $\omega$ is the solar time angle. 
Using Equation (2), we calculated the clearness index for GHI and UVER, which are referred to here as $K_{T}$ and $K_{T U V E R}$, respectively. $K_{T}$ can be used as an indicator of the general transmittance of the atmosphere, as it accounts for the total solar radiation transmitted to the surface from the TOA.

\subsubsection{Radiative Amplification Factor (RAF) for Ozone}

Erythemal UV is strongly absorbed by ozone. Therefore, to compare the effects of meteorological factors on $\mathrm{K}_{\mathrm{T}}$ and $\mathrm{K}_{\mathrm{TUVER}}$, it is necessary to fix the effect of ozone on $\mathrm{K}_{\mathrm{TUVER}}$. In this study, the radiative amplification factor (RAF) for ozone, first designed by Madronich [27], was used to convert observational UVER into values equivalent to slant ozone. The RAF for SCD is defined as the slope between the natural logarithms of SCD and UVER:

$$
\ln [\mathrm{UVER}]=\mathrm{RAF} \times \ln [\mathrm{SCD}]+\text { Const. }
$$

A $1 \%$ decrease of SCD leads to an RAF\% change in UVER. In general, TOC is used to calculate RAF of ozone [27], however, in this study SCD, which includes the effects of TOC and optical path was used. Similarly, Serrano et al. [28] used the slant column density of ozone in the calculation of RAF to figure out the sensitivity of UVER transmissivity to the total ozone column and actual optical path.

Then, using the RAF for SCD, the UVER for various SCDs can be converted to a modified UVER with a fixed ozone amount. The annual mean TOC values are $325( \pm 6.4), 319( \pm 6.2), 306( \pm 5.8)$, and 300 ( \pm 5.5$)$ DU at Gangneung, Pohang, Mokpo, and Gosan, respectively (Table 1). In this study, the SCD was set to $300 \mathrm{DU}$, corresponding to the minimum solar zenith angle (i.e., at noon) and lowest ozone conditions in South Korea. The UVER with fixed SCD is referred to as UVER 300 . The conversion formula for UVER using the RAF is

$$
\mathrm{UVER}_{300}=\operatorname{UVER}\left[1+\frac{300-\mathrm{SCD}}{300} \times \mathrm{RAF}\right]
$$

Using UVER $_{300}$ which implicates the attenuating effect of other absorbers such as clouds and aerosols except for SCD, a comparison of the influence of clouds and aerosols on UVER and GHI becomes possible. In addition, a new clearness index, $\mathrm{K}_{\text {TUVER300, }}$ can be defined for $\mathrm{UVER}_{300}$.

\subsubsection{Multiple Linear Regression Analysis}

A multiple linear regression (MLR) analysis was conducted to compare the individual contributions of the influencing factors to GHI and UVER. The dependent variables used in the regression analysis are $\mathrm{K}_{\mathrm{T}}, \mathrm{K}_{\mathrm{TUVER}}$, and $\mathrm{K}_{\mathrm{TUVER} 300}$, which are the clearness indices of each radiation dose (GHI, UVER, and UVER $_{300}$, respectively). The independent variables are CC, AOD, and SCD. The SCD is included only if the dependent variable is $\mathrm{K}_{\text {TUVER }}$. Because ozone amount has a negligible influence on GHI, $\mathrm{K}_{\mathrm{T}}$ does not take SCD as an input variable in MLR.

From the multiple regression analysis, individual contributions are calculated by multiplying the partial correlation coefficient and the beta coefficient between the dependent variable and the independent variables. The sum of these individual contributions is the determination coefficient $\left(R^{2}\right)$ of the regression model [29].

\section{Results}

\subsection{GHI and UVER Transmittance Differences}

Figure 2 shows the monthly average values of daily cumulative GHI and UVER for the period 2005-2016 at the four sites in South Korea. There is a good correlation between GHI and UVER at all sites. This correlation was the basis for many previous studies that estimated UV or UVER from GHI [6,8,9,30-32]. However, as is evident in Figure 2, the maximum values of GHI and UVER occur in different months: May for GHI and July-August for UVER. The maximum values of GHI 
at Gangneung, Pohang, Mokpo, and Gosan are 19.6, 19.5, 19.6, and $20.5 \mathrm{MJ} \mathrm{m}^{-2} \mathrm{day}^{-1}$, respectively, and they all occur in May. The maximum values for UVER are 2.7 (Gangneung) and $3.4 \mathrm{~kJ} \mathrm{~m}^{-2} \mathrm{day}^{-1}$ (Mokpo) in August, and 3.3 (Pohang) and $3.6 \mathrm{~kJ} \mathrm{~m}^{-2}$ day $^{-1}$ (Gosan) in July.

(a) Gangneung

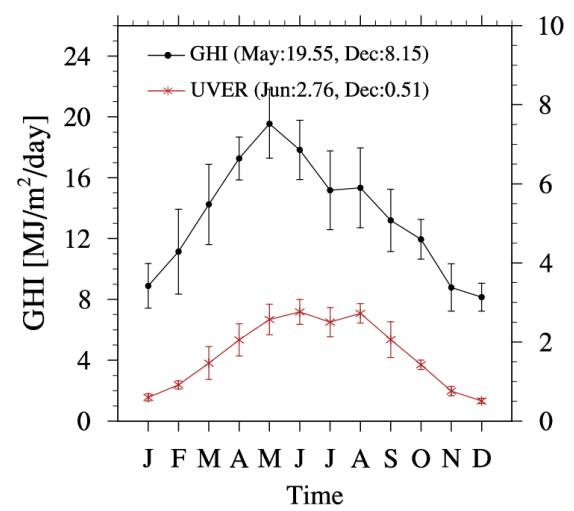

(c) Mokpo

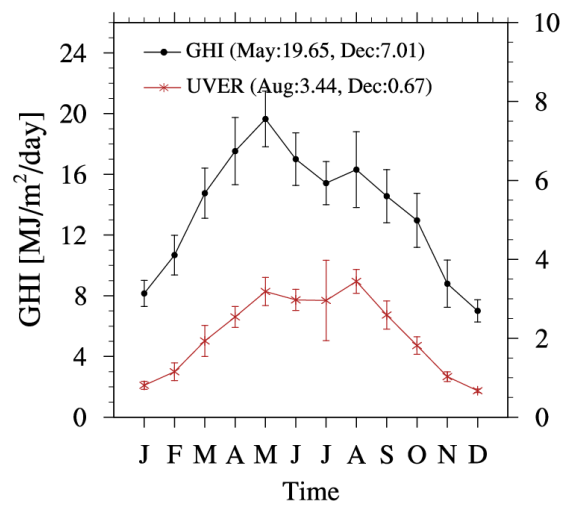

(c) (b) Pohang

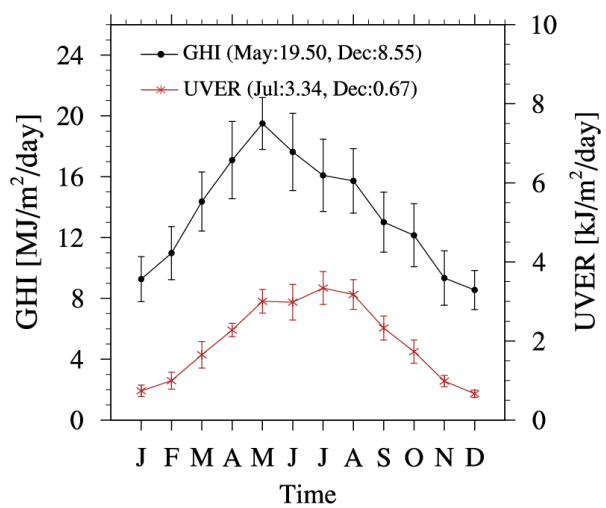

(b)

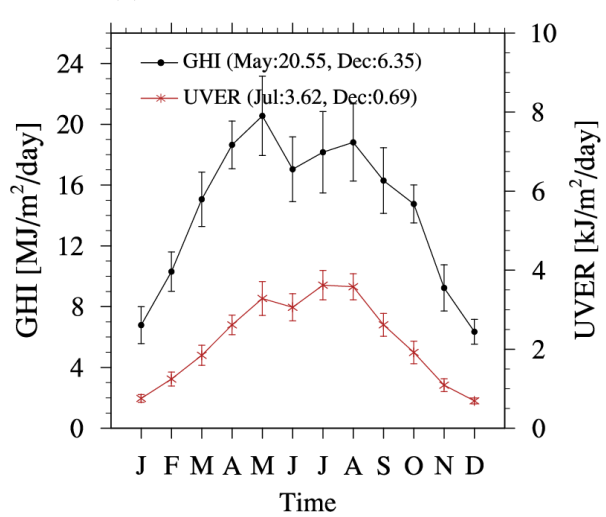

(d)

Figure 2. Monthly mean values of daily accumulated global solar radiation (black filled circle) and erythemal UV radiation (red asterisk) at (a) Gangneung, (b) Pohang, (c) Mokpo, and (d) Gosan.

The Korean Peninsula experiences a strong rainy season, called the "Changma", which is caused by a humid southeast monsoon system in summer (June to August) that leads to cloudiness. Therefore, although the highest sunlight occurs in summer, usually in June, the frequent shielding of solar radiation due to cloud formation and precipitation associated with the rainy season causes the monthly GHI in summer to be lower than that in May. In Gosan, located on Jeju Island, the monthly average GHI is lower in June than in July, unlike the other sites (Figure 2d). This may be caused by more frequent overcast skies and the occurrence of mist associated with southeasterly seasonal winds that bring high humidity and sea salt concentrations in June [33]. Canada et al. [25] reported monthly means of the daily cumulative GHI and UVER in Valencia $\left(39.5^{\circ} \mathrm{N}\right)$, Spain. The highest monthly mean values of GHI and UVER (25.1 Wm $\mathrm{Wm}^{-2}$ and $0.0041 \mathrm{Wm}^{-2}$, respectively) were observed in July. Because Valencia is hot and dry in summer, it experiences the highest values of both types of radiation in July. However, the Korean Peninsula, although it is a mid-latitude region like Valencia, experiences different radiative trends due to differences in its climate.

The GHI values at the four sites decrease after they reach their maximum values in May. However, the UVER values remain relatively constant during summer before decreasing rapidly after August. Surface UVER is primarily attenuated by stratospheric ozone. In the mid-latitude Northern Hemisphere, the maximum stratospheric ozone occurs in spring and decreases until it reaches a minimum in Autumn. 
High sunlight in summer and the decrease in stratospheric ozone cause UVER to remain high during the summer in Korea.

Differences in the monthly variation of GHI and UVER are due to the differing effects of attenuating factors. It is also possible to diagnose differences in GHI and UVER attenuation by analyzing the variability of the ratio UVER/GHI with the clearness index for $\mathrm{GHI}\left(\mathrm{K}_{\mathrm{T}}\right) ; \mathrm{K}_{\mathrm{T}}$ indicates the atmospheric transmittance of total solar radiation. If the ratio UVER/GHI changes with $\mathrm{K}_{\mathrm{T}}$, this means that $\mathrm{GHI}$ and UVER are affected differently by atmospheric conditions during their transit through the atmosphere. Figure 3 shows UVER/GHI as a function of $\mathrm{K}_{\mathrm{T}}$. The UVER/GHI ratio tends to increase with decreasing $\mathrm{K}_{\mathrm{T}}$, indicating that the more turbid the atmosphere, the higher the ratio of UVER to GHI. Indeed, both GHI and UVER decrease as the atmosphere is made more turbid by attenuating factors (clouds and aerosols). As daily mean CC increases from 3 to 5, daily accumulated GHI and UVER decrease from $26.1 \mathrm{MJ} \mathrm{m}^{-2}$ to $22.8 \mathrm{MJ} \mathrm{m}^{-2}$ and from $4.3 \mathrm{~kJ} \mathrm{~m}^{-2}$ to $3.9 \mathrm{~kJ} \mathrm{~m}^{-2}$, respectively, during the analysis period on average at the four sites. Likewise, as the daily mean AOD increases by 0.5 , GHI and UVER decrease by $2.4 \mathrm{MJ} \mathrm{m}^{-2}$ and $0.9 \mathrm{~kJ} \mathrm{~m}^{-2}$ per day. Although both GHI and UVER decrease with increasing clouds and aerosols, the fact that UVER/GHI is not constant to varying $\mathrm{K}_{\mathrm{T}}$ implies the existence of clear, different effects of attenuating factors on GHI and UVER.

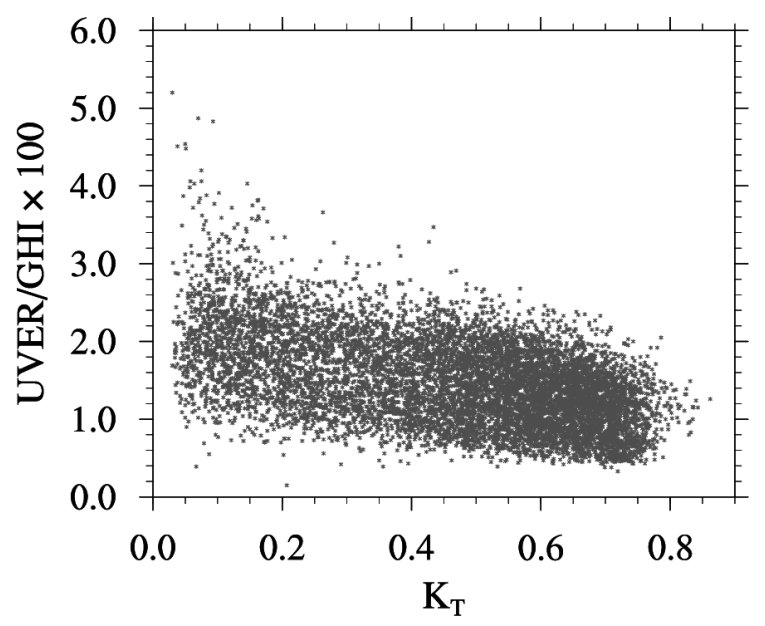

Figure 3. Relationship between $\mathrm{K}_{\mathrm{T}}$ and ultraviolet erythemal irradiance/global horizontal irradiance (UVER/GHI) at the four sites.

The trend of UVER/GHI with $\mathrm{K}_{\mathrm{T}}$ is consistent with previous studies [10,12]. Anton et al. [12] showed that UVER/GHI increases with decreasing $\mathrm{K}_{\mathrm{T}}$ in three regions of mid-western Spain: Badajoz $\left(38.99^{\circ} \mathrm{N}\right)$, Caceres $\left(39.48^{\circ} \mathrm{N}\right)$, and Plasencia $\left(40.06^{\circ} \mathrm{N}\right)$. The UVB/GHI [34] and UV/GHI [30,35-39] ratios have also been shown to increase with decreasing $\mathrm{K}_{\mathrm{T}}$. Many of these studies, however, have attributed this relationship to differences in the effects of clouds on GHI and UV, and have suggested that $\mathrm{K}_{\mathrm{T}}$ is related to cloud cover in the study region. Clouds also make a larger contribution to $\mathrm{K}_{\mathrm{T}}$ than do other factors in South Korea, according to the statistical analysis of Jung et al. [23]. However, $\mathrm{K}_{\mathrm{T}}$ is affected by other atmospheric constituents, including aerosols. Thus, it is necessary to examine the individual effects of multiple factors (clouds and aerosols in this study) on variations in GHI and UVER.

\subsection{Comparison of Two Clearness Indices}

In this section, results from a comparison of the clearness indices of GHI and UVER are presented. Figure 4 shows scatter plots of daily $\mathrm{K}_{\mathrm{T}}$ and $\mathrm{K}_{\mathrm{TUVER}}$ at the four sites during the analysis period. As $\mathrm{K}_{\mathrm{T}}$ increases, generally $K_{\text {TUVER }}$ also increases, but explanations of $K_{T}$ to $K_{\text {TUVER }}$ are insufficient with a large dispersion of data points. A linear fit of $K_{T U V E R}$ to $K_{T}$ yields determination coefficients $\left(R^{2}\right)$ of 0.26 (Gangneung), 0.30 (Pohang), 0.43 (Mokpo), and 0.62 (Gosan) at the four sites. $\mathrm{K}_{\mathrm{T}}$ and $\mathrm{K}_{\mathrm{TUVER}}$ are most strongly correlated at Gosan, followed by Mokpo, Pohang, and Gangneung. These regional 
differences can be attributed to spatial variations in stratospheric ozone in the study area. Stratospheric ozone at the analysis sites varied with latitude, with annual slant ozone amounts of 480 (Gangneung), 457 (Pohang), 434 (Mokpo), and 406 (Gosan) DU (Table 1). In addition, the annual variability in stratospheric ozone differs by location. Park et al. [40] used the total ozone column observed by remote-sensing during 1991-2009 to determine that the average annual variability in stratospheric ozone increases with latitude throughout the Korean Peninsula. Latitudinal differences in stratospheric ozone and its variability may be reflected in the correlation between $\mathrm{K}_{\mathrm{T}}$ and $\mathrm{K}_{\mathrm{TUVER}}$.

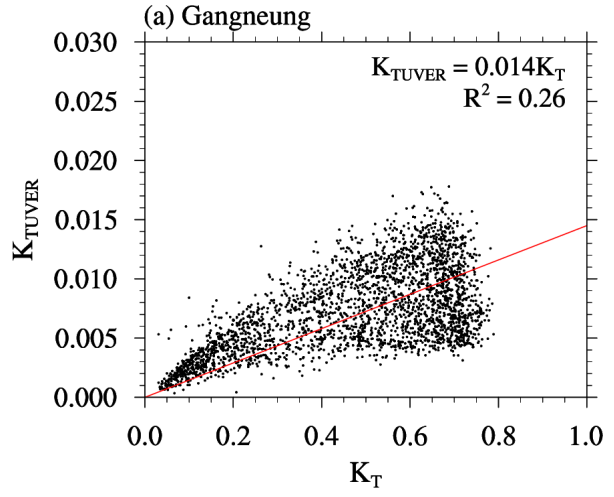

(a)

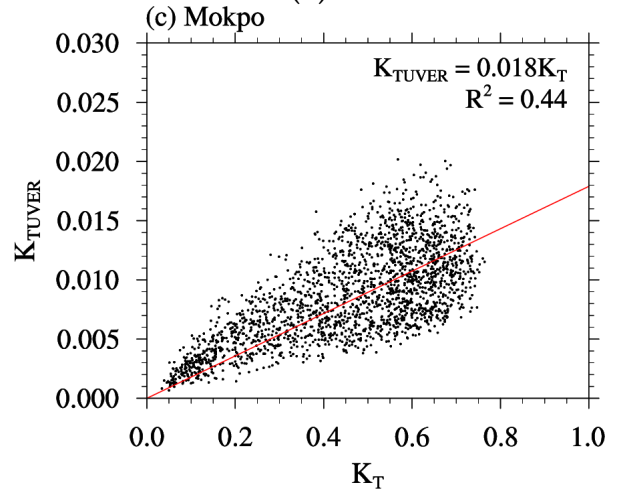

(c)

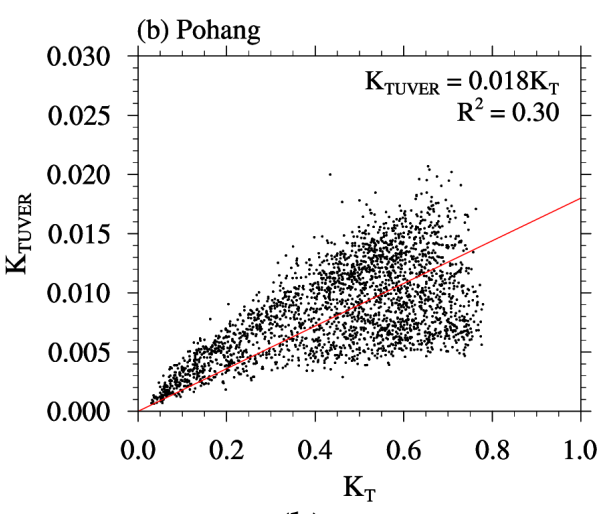

(b)

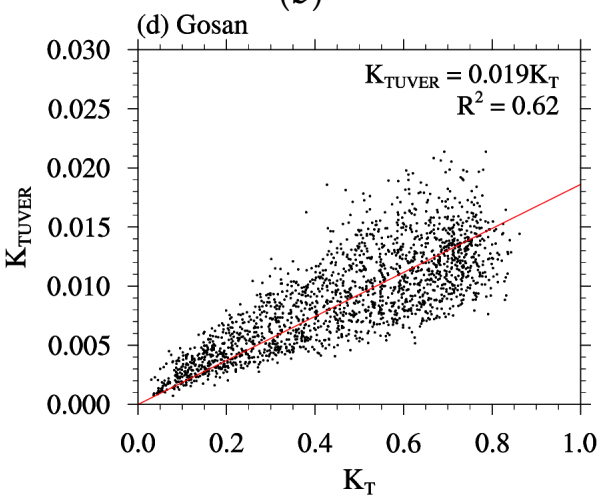

(d)

Figure 4. Relationship between $\mathrm{K}_{\mathrm{TUVER}}$ and $\mathrm{K}_{\mathrm{T}}$ at (a) Gangneung, (b) Pohang, (c) Mokpo, and (d) Gosan. The red line is the linear regression line.

To compare the transmittance of GHI and UVER without the effects of ozone and solar zenith angle, we analyzed the relationship between $\mathrm{K}_{\mathrm{T}}$ and $\mathrm{K}_{\mathrm{TUVER} 300}$ with the slant ozone fixed at $300 \mathrm{DU}$. As expected, and shown in Figure 5, $\mathrm{K}_{\mathrm{T}}$ and $\mathrm{K}_{\mathrm{TUVER}}$ are more strongly correlated than in Figure 4; i.e., the data points are more tightly clustered around the linear regression line. The $\mathrm{R}^{2}$ increases to 0.85 , 0.84, 0.70, and 0.72 at Gangneung, Pohang, Mokpo, and Gosan, respectively, compared with the $\mathrm{R}^{2}$ in Figure 4. However, a somewhat curved shape is noticeable in the scatter plot, with more data points above the regression line at lower $\mathrm{K}_{\mathrm{T}}$. The reason why $\mathrm{K}_{\mathrm{T}}$ is not perfectly linearly related to UVER, despite the fixed slant ozone effect, is that atmospheric attenuating factors have different effects on the various types of radiation. Wang et al. [38] suggested that for cloudy skies with low $\mathrm{K}_{\mathrm{T}}$, UV radiation is less attenuated than is global solar radiation, and they found that the relationship between the transmittance of GHI and UV is better fitted by a third-order polynomial curve than by a straight line. Their determination coefficient improved from 0.927 (linear) to 0.936 (third-order polynomial) when making this substitution. 


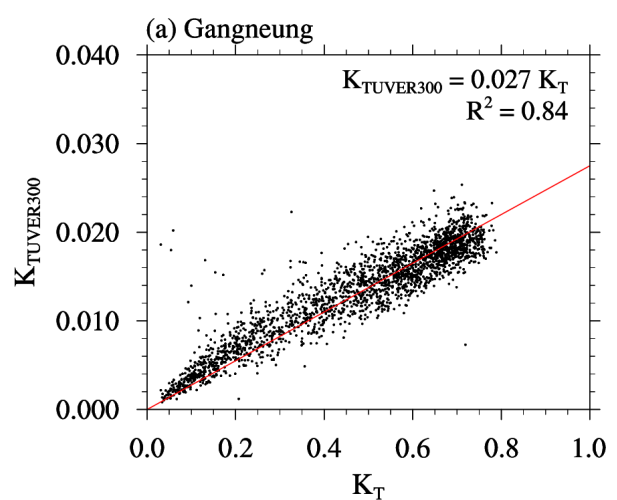

(a)

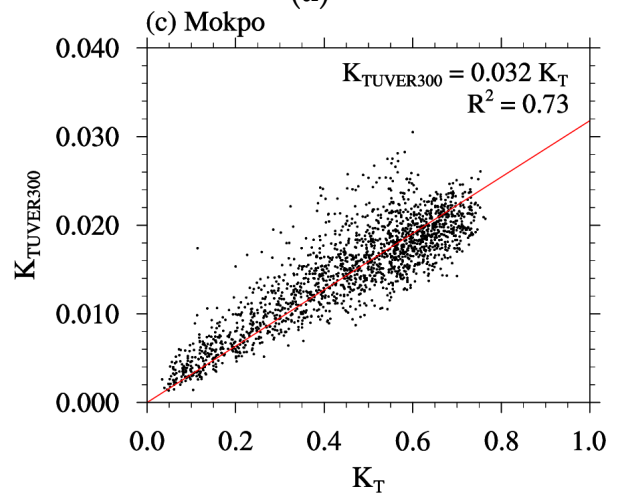

(c)

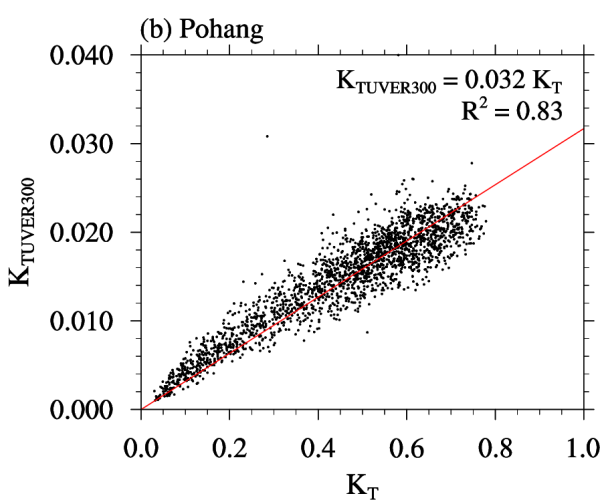

(b)

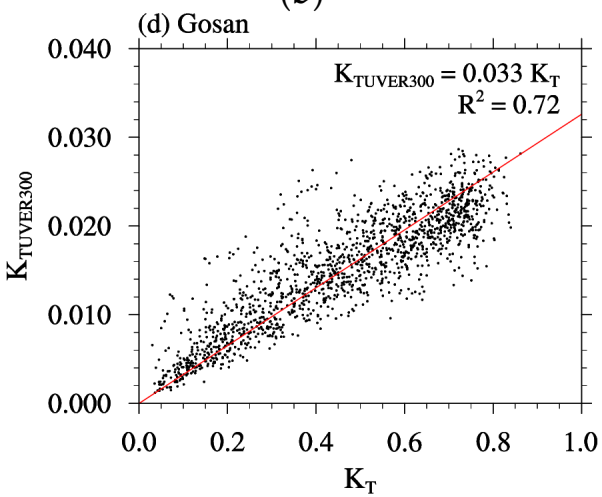

(d)

Figure 5. Relationship between $K_{\text {TUVER300 }}$ and $K_{T}$ at (a) Gangneung, (b) Pohang, (c) Mokpo, and (d) Gosan. The red line is the linear regression line.

The degree of increase in the correlation between $\mathrm{K}_{\mathrm{T}}$ and $\mathrm{K}_{\mathrm{TUVER} 300}$ that is obtained by fixing the slant ozone effect is largest at the Gangneung site (0.26 to 0.85) and smallest at the Gosan site (0.62 to 0.72). This demonstrates that the effect of ozone on $\mathrm{K}_{\text {TUVER }}$ is greater at higher-latitude sites. Moreover, the correlations shown in Figure 5 are highest in Gangneung followed by Pohang, Mokpo, and Gosan, unlike the trend shown in Figure 4. This difference in correlation may be due to differing regional characteristics of clouds and/or aerosols among the four sites. At Gangneung, which shows the greatest increase in $R^{2}$, the annual average CC is $5.1( \pm 1.4)$ and the AOD is $0.33( \pm 0.11)$, whereas at Gosan, where the increase was smallest, the average CC and AOD are $6.1( \pm 0.8)$ and $0.38( \pm 0.09)$, respectively. Therefore, even though the effects of ozone are fixed, the correlation of $\mathrm{K}_{\mathrm{TUVER}} 300$ with $\mathrm{K}_{\mathrm{T}}$ at Gosan is lower than in other regions because of the greater effects of abundant clouds and aerosols.

\subsection{Differing Effects of Clouds and Aerosols on GHI and UVER}

A correlation analysis between the clearness indices ( $\left.\mathrm{K}_{\mathrm{T}}, \mathrm{K}_{\mathrm{TUVER}}, \mathrm{K}_{\mathrm{TUVER} 300}\right)$ and attenuating factors (CC, AOD, and SCD) was carried out to evaluate the effects of the latter. For $\mathrm{K}_{\mathrm{T}}$ and $\mathrm{K}_{\mathrm{TUVER}}$ (00, which are considered to be unaffected by slant ozone variations, only the correlations with $\mathrm{CC}$ and AOD were analyzed, whereas for $\mathrm{K}_{\mathrm{TUVER}}$ the correlation with SCD was also included. The correlation coefficients are summarized in Table 2. All variables at the four sites have negative correlations with the clearness indices. $\mathrm{K}_{\mathrm{T}}$ has a high negative correlation with $\mathrm{CC}$, with a four-site average correlation coefficient of -0.84 . The AOD has an average correlation coefficient of -0.30 with $\mathrm{K}_{\mathrm{T}}$. Jung et al. [23] analyzed the correlation between $\mathrm{K}_{\mathrm{T}}$ and $\mathrm{CC}, \mathrm{AOD}$, and relative humidity, and reported significant negative coefficients of -0.72 and -0.37 for $C C$ and $A O D$, respectively, on average in Korea during the period 2000-2015. 
Table 2. Correlation coefficients between clearness indices and atmospheric attenuating factors (CC, AOD, and SCD) at each site.

\begin{tabular}{ccccc}
\hline & Site & CC & AOD & SCD \\
\hline \multirow{4}{*}{$\mathrm{K}_{\mathrm{T}}$} & Gangneung & -0.85 & -0.34 & \\
& Pohang & -0.84 & -0.28 & \\
& Mokpo & -0.84 & -0.25 & \\
& Gosan & -0.84 & -0.33 & \\
& AVERAGE & -0.84 & -0.30 & \\
\hline \multirow{3}{*}{$\mathrm{K}_{\text {TUVER }}$} & Gangneung & -0.37 & -0.20 & -0.44 \\
& Pohang & -0.36 & -0.16 & -0.47 \\
& Mokpo & -0.53 & -0.21 & -0.50 \\
& Gosan & -0.59 & -0.34 & -0.48 \\
& AVERAGE & -0.46 & -0.23 & -0.47 \\
\hline \multirow{2}{*}{$\mathrm{K}_{\text {TUVER300 }}$} & Gangneung & -0.83 & -0.42 & \\
& Pohang & -0.81 & -0.36 & \\
& Mokpo & -0.77 & -0.38 & \\
& Gosan & -0.79 & -0.46 & \\
\hline & AVERAGE & -0.80 & -0.41 & \\
\hline
\end{tabular}

As the $\mathrm{K}_{\text {TUVER }}$ has a large negative correlation with SCD, it is necessary to analyze the relationship between $\mathrm{K}_{\text {TUVER300 }}$ and the attenuating factors for comparison with $\mathrm{K}_{\mathrm{T}}$. The $\mathrm{K}_{\text {TUVER300 }}$ has higher correlation coefficients with clouds and aerosols than does $\mathrm{K}_{\mathrm{TUVER}}$. The average correlation coefficient of CC with UVER transmittance increased from -0.46 (with $\mathrm{K}_{\mathrm{TUVER}}$ ) to -0.80 (with $\mathrm{K}_{\mathrm{TUVER} 300}$ ). For AOD, the negative correlation also increased from -0.23 (with $\mathrm{K}_{\text {TUVER }}$ ) to -0.41 (with $\mathrm{K}_{\text {TUVER300 }}$ ).

A correlation analysis confirmed that in general, the greater the attenuating factor, the lower the clearness index. However, there is a difference in the correlation coefficient between each factor and clearness index. The CC has a stronger correlation with $\mathrm{K}_{\mathrm{T}}$ than with $\mathrm{K}_{\mathrm{TUVER} 300}$ and the AOD has a stronger correlation with $\mathrm{K}_{\mathrm{TUVER} 300}$ than with $\mathrm{K}_{\mathrm{T}}$. To identify the individual effects of the attenuating factors, the dependence of three parameters $\left(\mathrm{K}_{\mathrm{T}}, \mathrm{K}_{\mathrm{TUVER} 300}\right.$, and $\left.\mathrm{UVER}_{300} / \mathrm{GHI}\right)$ on clouds and aerosols was investigated.

Figure 6a shows the relationships of $\mathrm{UVER}_{300} / \mathrm{GHI}, \mathrm{K}_{\mathrm{TUVER} 300}$, and $\mathrm{K}_{\mathrm{T}}$ with CC. The two clearness indices decrease with increasing CC, whereas $\mathrm{UVER}_{300} / \mathrm{GHI}$ increases with increasing CC. The UVER 300 / GHI trend clearly shows that clouds more efficiently attenuate GHI than UVER. Buntoung et al. [10] analyzed changes in UVER/GHI with $\mathrm{K}_{\mathrm{T}}$ in Thailand under conditions of fixed solar zenith angle $\left(30^{\circ}\right)$, ozone ( $\left.300 \mathrm{DU}\right)$, precipitable water $(2 \mathrm{~cm})$, and aerosol concentrations (regional climatology), and found a higher transmittance for UVER than for GHI under cloudy conditions (low $\mathrm{K}_{\mathrm{T}}$ ). However, unlike our analysis, they assumed $\mathrm{K}_{\mathrm{T}}$ to be solely related to cloud cover. The UVER $300 / \mathrm{GHI}$ ratio also noticeably increases with cloudiness ( $>5$ octas), indicating that the wavelength dependence of solar radiation attenuation is reinforced with increasing cloudiness. Under cloudy skies, incoming solar radiation is reflected by clouds and undergoes Rayleigh scattering by atmospheric constituents. Because the Rayleigh scattering coefficient is greater at shorter wavelengths, backscattered light contributes to a larger increase in short-wave irradiance than in long-wave radiation [14,17]. After passing through clouds, Rayleigh backscattering of sunlight beneath the cloud and reflection from the cloud bottom toward the ground also contribute to a larger decrease in GHI than in UVER [15].

To examine the effects of AOD, which has a lower correlation with the clearness indices than do CC and SCD (Table 2), an AOD analysis was performed for clear sky conditions $(C C<3)$. This analysis included fixing the effects of clouds and slant ozone, and evaluating the variations of UVER $300 / G H I$, $\mathrm{K}_{\text {TUVER300, and }} \mathrm{K}_{\mathrm{T}}$ with AOD (Figure $6 \mathrm{~b}$ ). Unlike the results for CC, all parameters show a decreasing trend with increasing AOD. UVER ${ }_{300} / \mathrm{GHI}$ decreases from $0.0195 \%( \pm 0.0027 \%)$ when AOD is at a minimum $(0.05-0.15)$ to $0.0195 \%( \pm 0.0028 \%)$ when $\mathrm{AOD}$ is at a maximum $(0.95-1.05)$, suggesting that AOD reduces UVER more effectively than GHI. A decrease in the ratio of UVER to GHI with 
increasing AOD is also evident in results from previous studies [10,12,41]. Anton et al. [12] found that the UVER/GHI ratio increases from $0.0195 \%$ to $0.0231 \%$ as AOD increases when the ozone is fixed in the range 320-340 DU and explained that the higher attenuation of UVER is partially caused by absorption by aerosols itself, tropospheric ozone, and other anthropogenic gases, due to the increase in the optical path caused by scattering, which is consistent with previous studies [42-44]. Erlick and Frederick [19] modeled UV and visible transmittance by various types of aerosols. They found that the transmittance of spectral solar irradiance is smaller at shorter wavelengths because of a combination of attenuation by ozone below $\sim 320 \mathrm{~nm}$ and a sharp increase in the absorption coefficient of water-soluble aerosols below $~ 340$ in an increased light path by multiple scattering. Although absorption by aerosols varies with aerosol type, this study focuses on the difference in the overall attenuating effects of aerosols on GHI and UVER over the Korean Peninsula.

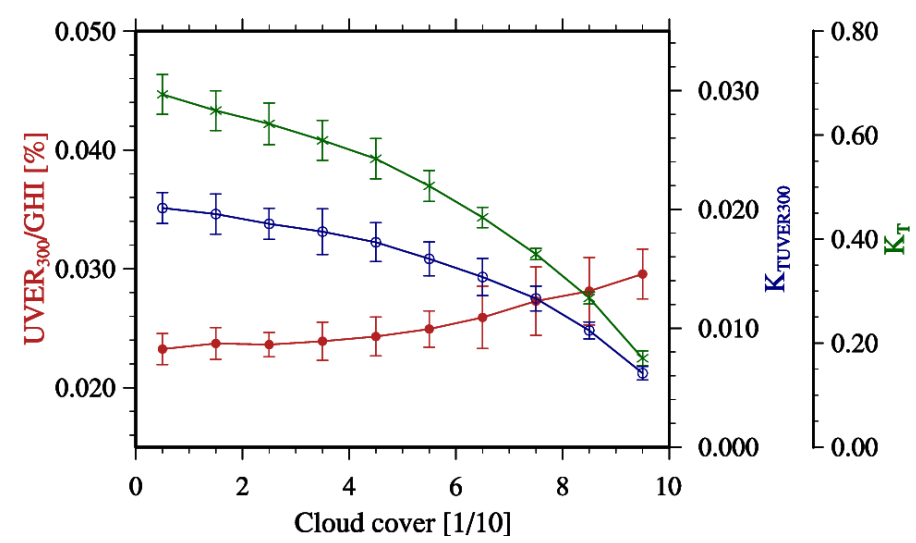

(a)

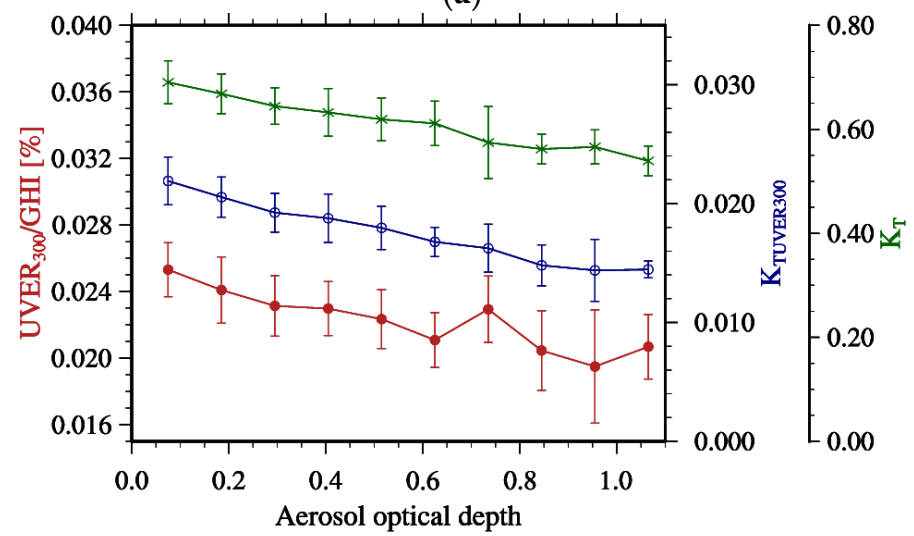

(b)

Figure 6. Dependence of $\mathrm{UVER}_{300} / \mathrm{G}$ (red filled circle) and two clearness indices, $\mathrm{K}_{\mathrm{T}}$ (green asterisk) and $K_{\text {TUVER300 }}$ (blue open circle), on (a) cloud cover and (b) aerosol optical depth.

\subsection{Analysis of Individual Contributions of Attenuating Factors Using MLR}

In Section 3.3, the dependence of GHI and UVER transmittance on CC and AOD were shown to differ. To examine this difference quantitatively, the contribution of each variable to changes in the clearness indices was determined by multiple regression analysis. As in the correlation analysis, the regression analyses for $\mathrm{K}_{\mathrm{T}}$ and $\mathrm{K}_{\mathrm{TUVER} 300}$ use CC and AOD as the independent variables, and the $\mathrm{K}_{\text {TUVER }}$ regression analysis includes SCD in addition to these two variables. Multiple linear regression results for the three dependent variables are summarized in Table 3. For $\mathrm{K}_{\mathrm{T}}$, the determination coefficient is 0.71 , averaged over the four sites. This means that $\sim 71 \%$ of $\mathrm{K}_{\mathrm{T}}$ can be explained by CC and AOD in South Korea. Of the two independent variables, CC makes the dominant contribution $(69 \%)$ with small regional deviations $(<3 \%)$. The contribution of AOD was small $(\sim 2 \%)$ compared with that of CC. 
In the $\mathrm{K}_{\mathrm{TUVER}}$ model, CC and SCD make the largest contributions to UVER transmittance, whereas the contribution of AOD is insignificant (2.1\%-3.9\%) compared with those of CC and SCD, except for in Gosan (8.1\%). The regression analysis of $\mathrm{K}_{\mathrm{TUVER}} 300$ with CC and AOD results in a determination coefficient of 0.68 , with contributions of $60 \%$ for CC and $8 \%$ for AOD, on average for the four sites.

Table 3. Determination coefficients $\left(\mathrm{R}^{2}\right)$ and individual contributions (\%) of each attenuating factor determined by multiple linear regression (MLR) analysis at each site.

\begin{tabular}{cccccc}
\hline & Site & $\mathbf{R}^{2}$ & CC & AOD & SCD \\
\hline \multirow{4}{*}{$\mathrm{K}_{\mathrm{T}}$} & Gangneung & 0.72 & 70.5 & 1.2 & \\
& Pohang & 0.71 & 69.9 & 1.1 & \\
& Mokpo & 0.71 & 68.9 & 1.8 & \\
& Gosan & 0.71 & 67.7 & 3.5 & \\
& AVERAGE & 0.71 & 69.2 & 1.9 & \\
\hline \multirow{5}{*}{$\mathrm{K}_{\text {TUVER }}$} & Gangneung & 0.62 & 25.1 & 2.6 & 34.2 \\
& Pohang & 0.62. & 23.5 & 2.1 & 36.5 \\
& Mokpo & 0.65 & 30.8 & 3.9 & 30.4 \\
& Gosan & 0.68 & 33.3 & 8.1 & 27.0 \\
& AVERAGE & 0.65 & 28.2 & 4.2 & 32.0 \\
\hline \multirow{3}{*}{$\mathrm{K}_{\text {TUVER300 }}$} & Gangneung & 0.71 & 64.8 & 5.7 & \\
& Pohang & 0.68 & 62.6 & 5.8 & \\
& Mokpo & 0.65 & 55.7 & 8.9 & \\
& Gosan & 0.68 & 56.3 & 11.5 & \\
\hline
\end{tabular}

Comparing the contributions of each independent variable in the models of $\mathrm{K}_{\mathrm{T}}$ and $\mathrm{K}_{\text {TUVER300, }}$, the contribution of CC in $\mathrm{K}_{\mathrm{TUVER} 300}(59.6 \%)$ is $\sim 10 \%$ lower than in $\mathrm{K}_{\mathrm{T}}(69.2 \%)$. This agrees with the attenuation of solar radiation by CC being greater for GHI than for UVER, as discussed in Section 3.3. In South Korea, on average, clouds contribute $10 \%$ more to GHI than to UVER, with regional differences of $5.7 \%, 7.2 \%, 14.3 \%$, and $11.4 \%$ in Gangneung, Pohang, Mokpo, and Gosan, respectively.

However, the contribution of aerosols from the $\mathrm{K}_{\text {TUVER300 }}$ regression (8.1\%) with a fixed slant ozone effect is larger than that of $\mathrm{K}_{\mathrm{T}}(1.9 \%)$, indicating again that the attenuation of UVER by aerosols is less than that of GHI. The differences in aerosol effects are greater in Mokpo (7.4\%) and Gosan (8.0\%) than in Gangneung (4.5\%) and Pohang (4.8\%).

Differences in the relative contributions of clouds and aerosols to GHI and UVER variations may be caused by differences in the distribution of attenuating factors. Even though our analysis area (South Korea) is small, this region is affected by prevailing seasonal monsoon and is surrounded by water on three sides. This creates regional differences in cloudiness with season.

In addition, as South Korea is located on the eastern coast of Asia, the transport of inland pollutants and yellow dust causes regional differences in aerosol loading and type. Emissions from local sources such as industrial complexes and factories also have a significant impact on regional differences in aerosols in South Korea. For example, Lee et al. [45] categorized regional aerosol type by using a number of known aerosol classification methods for five sites in Korea, based on aerosol optical property data obtained from AERONET sun photometer measurements during the Megacity Air Pollution Studies-Seoul (MAPS-Seoul). They found that the inland mid-western region (sites in metropolitan areas) and the eastern coast are affected by local pollutants from urban or suburban areas where highly absorbing aerosols form a large portion of the total aerosols, whereas Gosan, located on Jeju Island in the south, is affected by non-absorbing fine-mode aerosols from southern ocean regions. They also found that coarse mode aerosols are dominant on an island off the western coast (Anmyon), and are likely caused by transport from eastern China and sea salt from the Yellow Sea. Hence, South Korea has regionally diverse aerosol characteristics due to the effects of local pollution, 
airflow, and geographic location, which induce regional differences in the contribution of aerosols to GHI and UVER.

\section{Summary and Discussion}

This study evaluated and compared the effects of clouds and aerosols on GHI and UVER using data from four sites in South Korea-Gangneung, Pohang, Mokpo, and Gosan-during the period 2005-2016. The UVER/GHI ratios increase with decreasing $K_{T}$, suggesting that UVER and GHI are affected differently by various attenuating factors. The relationship between $K_{T}$ and $K_{T U V E R}$ was evaluated at each site, with determination coefficients of 0.26 (Gangneung), 0.30 (Pohang), 0.43 (Mokpo), and 0.62 (Gosan) at the four sites. By fixing the slant ozone to $300 \mathrm{DU}$, the correlation of the clearness index of UVER ( $\mathrm{K}_{\mathrm{TUVER} 300}$ ) with $\mathrm{K}_{\mathrm{T}}$ increased at all sites to 0.85 (Gangneung), 0.84 (Pohang), 0.70 (Mokpo), and 0.72 (Gosan). However, $\mathrm{K}_{\mathrm{T}}$ is not perfectly linearly correlated with $\mathrm{K}_{\text {TUVER300 }}$ because of the differing effects of clouds and aerosols on GHI and UVER. Interestingly, regional differences in the improvement of the correlation were found, with the greatest increase at Gangneung (59\%), followed by Pohang (54\%), Mokpo (37\%), and Gosan (10\%), in latitudinal order.

To compare the individual effects of clouds and aerosols on GHI and UVER, variations in $\mathrm{UVER}_{300} / \mathrm{GHI}$ with clouds and aerosols were analyzed. The $\mathrm{UVER}_{300} / \mathrm{GHI}$ ratio increased with cloud cover, indicating that clouds attenuate GHI more efficiently than UVER. In cloudy sky conditions, the incoming solar radiation is reflected by clouds and the light undergoes Rayleigh scattering by atmospheric constituents on an increased optical path. The scattered lights contribute to the increase of UVER more efficiently than GHI by wavelength dependence of the Rayleigh scattering coefficient. In the case of AOD, under clear sky conditions, $\mathrm{UVER}_{300} / \mathrm{GHI}$ decreased with increasing aerosol optical depth. This means the UVER attenuating effects of aerosols are greater than those of clouds. In an extended optical path by scattering, significant absorption by ozone, soluble aerosols, and other gases below $340 \mathrm{~nm}$ is one of the reasons that the attenuating effect of aerosols is more efficient on UVER than GHI.

To quantitatively confirm the differing effects of clouds and aerosols, multiple regression models of $\mathrm{K}_{\mathrm{T}}, \mathrm{K}_{\mathrm{TUVER}}$, and $\mathrm{K}_{\mathrm{TUVER} 300}$ were constructed using attenuating factors (clouds, aerosols, and ozone) as independent variables. On average, in South Korea, clouds contribute to $\sim 69 \%(71 \%, 70 \%, 69 \%$, and $68 \%$ at Gangneung, Pohang, Mokpo and Gosan) of the $\mathrm{K}_{\mathrm{T}}$ variations. For the $\mathrm{K}_{\mathrm{TUVER}} 300$ model, clouds make relatively small contributions of $65 \%, 63 \%, 56 \%$, and $56 \%$ to the $\mathrm{K}_{\text {TUVER } 300}$ variation at the four sites with an average contribution of $60 \%$. However, aerosol optical depth showed a relatively small contribution of $2 \%(1.2 \%, 1.1 \%, 1.8 \%$, and $3.5 \%$ at the four sites $)$ and a relatively large contribution of $8 \%\left(5.7 \%, 5.8 \%, 8.9 \%, 11.5 \%\right.$ at the four sites) to the variations in $\mathrm{K}_{\mathrm{T}}$ and $\mathrm{K}_{\mathrm{TUVER} 300}$, respectively.

We further evaluated the differing contributions of clouds and aerosols to GHI and UVER, and found differences by analysis sites that can be attributed to regional differences in climatic and geographical characteristics on the Korean Peninsula. The differing effects of clouds and aerosols to GHI and UVER found here, and the regional bias of these relationships in South Korea, can be used to guide model development for estimations of UVER using GHI in future studies.

Author Contributions: Conceptualization, J.K. and Y.G.L.; Data curation, Y.G.L.; Formal analysis, J.K.; Funding acquisition, Y.G.L.; Investigation, J.K., J.-H.K. and H.L.; Methodology, J.K., Y.G.L. and H.L.; Project administration, Y.G.L.; Software, J.K.; Supervision, Y.G.L.; Validation, J.K. and J.-H.K.; Visualization, J.K.; Writing-original draft, J.K. and Y.G.L.; Writing-review \& editing, Y.G.L., J.-H.K. and H.L. All authors have read and agreed to the published version of the manuscript.

Funding: This work was supported by the research fund of Chungnam National University (2018-0615-01).

Conflicts of Interest: The authors declare no conflict of interest.

\section{References}

1. Iqbal, M. An Introduction to Solar Radiation; Academic Press: Toronto, ON, Canada, 1983. 
2. McKinlay, A.; Diffey, B.L. A reference action spectrum for ultraviolet erythema in human skin. CIE J. 1987, 6, $17-22$.

3. McKenzie, R.L.; Matthews, W.A.; Johnston, P.V. The relationship between erythemal UV and ozone, derived from spectral irradiance measurements. Geophys. Res. Lett. 1991, 18, 2269-2272. [CrossRef]

4. Foyo-Moreno, I.; Alados, I.; Olmo, F.J.; Alados-Arboledas, L. The influence of cloudiness on UV global irradiance (295-385 nm). Agric. For. Meteorol. 2003, 120, 101-111. [CrossRef]

5. Murillo, W.; Cañada, J.; Pedrós, G. Correlation between global ultraviolet (290-385nm) and global irradiation in Valencia and Cordoba (Spain). Renew. Energ. 2003, 28, 409-418. [CrossRef]

6. Wang, L.; Gong, W.; Li, J.; Ma, Y.; Hu, B. Empirical studies of cloud effects on ultraviolet radiation in Central China: UV radiation in central China. Int. J. Climatol. 2014, 34, 2218-2228. [CrossRef]

7. Gandía, S.; Utrillas, M.P.; Gómez-Amo, J.L.; Esteve, A.R.; Estellés, V.; Pedrós, R.; Núñez, J.A.; Martínez Lozano, J.A. Relationship between UVB and broadband solar radiation in Spain: UVB and broadband solar radiation in Spain. Int. J. Climatol. 2015, 35, 1761-1771. [CrossRef]

8. Adam, M.E.-N. Determination of daily total ultraviolet-B in a subtropical region (Upper Egypt): An empirical approach. Atmos. Res. 2015, 153, 1-9. [CrossRef]

9. Antón, M.; Serrano, A.; Cancillo, M.L.; García, J.A. An empirical model to estimate ultraviolet erythemal transmissivity. Ann. Geophys. 2009, 27, 1387-1398. [CrossRef]

10. Buntoung, S.; Janjai, S.; Nunez, M.; Choosri, P.; Pratummasoot, N.; Chiwpreecha, K. Sensitivity of erythemal $\mathrm{UV} /$ global irradiance ratios to atmospheric parameters: Application for estimating erythemal radiation at four sites in Thailand. Atmos. Res. 2014, 149, 24-34. [CrossRef]

11. Gurrea, G.; Blanca-Giménez, V.; Pérez, V.; Serrano, M.-A.; Moreno, J.-C. Statistical Study and Prediction of Variability of Erythemal Ultraviolet Irradiance Solar Values in Valencia, Spain. Asia Pac. J. Atmos. Sci. 2018, 54, 599-610. [CrossRef]

12. Antón, M.; Serrano, A.; Cancillo, M.L.; García, J.A. Relationship between erythemal irradiance and total solar irradiance in southwestern Spain. J. Geophys. Res. 2008, 113, D14. [CrossRef]

13. Adam, M.E.-N. Atmospheric modulations of the ratio of UVB to broadband solar radiation: Effect of ozone, water vapour, and aerosols at Qena, Egypt. Int. J. Climatol. 2014, 34, 2477-2488. [CrossRef]

14. Kylling, A.; Albold, A.; Seckmeyer, G. Transmittance of a cloud is wavelength-dependent in the UV-range: Physical interpretation. Geophys. Res. Lett. 1997, 24,397-400. [CrossRef]

15. Frederick, J.E.; Erlick, C. The attenuation of sunlight by high-latitude clouds: Spectral dependence and its physical mechanisms. J. Atmos. Sci. 1997, 54, 2813-2819. [CrossRef]

16. Erlick, C.; Frederick, J.E.; Saxena, V.K.; Wenny, B.N. Atmospheric transmission in the ultraviolet and visible: Aerosols in cloudy atmospheres. J. Geophys. Res. 1998, 103, 31541-31555. [CrossRef]

17. Bartlett, J.S.; Ciotti, Á.M.; Davis, R.F.; Cullen, J.J. The spectral effects of clouds on solar irradiance. J. Geophys. Res. Ocean. 1998, 103, 31017-31031. [CrossRef]

18. Lindfors, A.; Arola, A. On the wavelength-dependent attenuation of UV radiation by clouds. Geophys. Res. Lett. 2008, 35, 253. [CrossRef]

19. Erlick, C.; Frederick, J.E. Effects of aerosols on the wavelength dependence of atmospheric transmission in the ultraviolet and visible: 2. Continental and urban aerosols in clear skies. J. Geophys. Res. Atmos. 1998, 103, 23275-23285. [CrossRef]

20. Kirchstetter, T.W.; Novakov, T.; Hobbs, P.V. Evidence that the spectral dependence of light absorption by aerosols is affected by organic carbon: Spectral light absorption by aerosols. J. Geophys. Res. Atmos. 2004, 109, D21. [CrossRef]

21. Lee, H.; Kim, W.; Lee, Y.G.; Koo, J.-H.; Jung, Y.; Park, S.S.; Cho, H.-K.; Kim, J. Broadband dependence of atmospheric transmissions in the UV and total solar radiation. Tellus B Chem. Phys. Meteorol. 2019, 71, 1503513. [CrossRef]

22. Lee, H.; Kim, W.; Lee, Y.G.; Kim, J.; Cho, H.K. Atmospheric transmission of ultraviolet and total solar radiation by clouds, aerosols, and ozone in Seoul, Korea: A comparison of semi-empirical model predictions with observations. Asia Pac. J. Atmos. Sci. 2019, 55, 165-175. [CrossRef]

23. Jung, Y.; Lee, H.; Kim, J.; Cho, Y.; Kim, J.; Lee, Y. Spatiotemporal characteristics in the clearness index derived from global solar radiation observations in Korea. Atmosphere 2016, 7, 55. [CrossRef]

24. Solar Light. UV-Biometer User's Manual; Solar Light Co.: Glenside, PA, USA, 1993. 
25. Cañada, J.; Esteve, A.R.; Marín, M.J.; Utrillas, M.P.; Tena, F.; Martínez-Lozano, J.A. Study of erythemal, UV (A + B) and global solar radiation in Valencia (Spain). Int. J. Climatol. 2008, 28, 693-702. [CrossRef]

26. El-Nouby Adam, M. Effect of the atmosphere on UVB radiation reaching the Earth's surface: Dependence on solar zenith angle. Atmos. Ocean. Sci. Lett. 2011, 4, 139-145. [CrossRef]

27. Madronich, S. UV radiation in the natural and perturbed atmosphere. In UV-B Radiation and Ozone Depletion: Effects on Humans, Animals, Plants, Microorganisms, and Materials; Tevini, M., Ed.; Lewis Publishers: Boca Raton, FL, USA, 1993; pp. 17-69.

28. Serrano, A.; Antón, M.; Cancillo, M.L.; García, J.A. Proposal of a new erythemal UV radiation amplification factor. Atmos. Chem. Phys. Discuss. 2008, 8, 1089-1111. [CrossRef]

29. Overall, J.E. Applied Multivariate Analysis; McGraw-Hill: New York, NY, USA, 1972.

30. Foyo-Moreno, I.; Vida, J.; Alados-Arboledas, L. Ground based ultraviolet (290-385 nm) and broadband solar radiation measurements in south-eastern Spain. Int. J. Climatol. 1998, 18, 1389-1400. [CrossRef]

31. Martinez-Lozano, J.A.; Tena, F.; Utrillas, M.P. Ratio of UV to global broad band irradiation in Valencia, Spain. Int. J. Climatol. 1999, 19, 903-911. [CrossRef]

32. Sabziparvar, A.A. Estimation of clear-sky effective erythema radiation from broadband solar radiation (300-3000 nm) data in an arid climate. Int. J. Climatol. 2009, 29, 2027-2032. [CrossRef]

33. Kim, Y.-A.; Choi, W. A study on the monthly characteristics of solar UV radiation in Gosan, Jeju. Atmosphere 2017, 27, 291-300, (In Korean with English abstract).

34. Cui, X.; Gu, S.; Zhao, X.; Wu, J.; Kato, T.; Tang, Y. Diurnal and seasonal variations of UV radiation on the northern edge of the Qinghai-Tibetan Plateau. Agric. For. Meteorol. 2008, 148, 144-151. [CrossRef]

35. Cañada, J.; Pedrós, G.; López, A.; Boscá, J.V. Influences of the clearness index for the whole spectrum and of the relative optical air mass on UV solar irradiance for two locations in the Mediterranean area, Valencia and Cordoba. J. Geophys. Res. Atmos. 2000, 105, 4759-4766. [CrossRef]

36. Ogunjobi, K.O.; Kim, Y.J. Ultraviolet $(0.280-0.400 \mu \mathrm{m})$ and broadband solar hourly radiation at Kwangju, South Korea: Analysis of their correlation with aerosol optical depth and clearness index. Atmos. Res. 2004, 71, 193-214. [CrossRef]

37. Santos, J.B.; Villán, D.M.; Castrillo, A.D.M. Analysis and cloudiness influence on UV total irradiation. Int. J. Climatol. 2011, 31, 451-460. [CrossRef]

38. Wang, L.; Gong, W.; Lin, A.; Hu, B. Measurements and cloudiness influence on UV radiation in Central China: Cloud effect on UV in central China. Int. J. Climatol. 2014, 34, 3417-3425. [CrossRef]

39. Gong, W.; Zhang, M.; Wang, L.; Hu, B.; Ma, Y. Measurement and estimation of ultraviolet radiation in Pearl River Delta, China. J. Atmos. Sol. Terr. Phys. 2015, 123, 63-70. [CrossRef]

40. Park, S.S.; Kim, J.; Cho, N.; Lee, Y.G.; Cho, H.K. The variations of stratospheric ozone over the Korean Peninsula. 1985-2009. Atmosphere 2011, 21, 349-359, (In Korean with English abstract).

41. de Miguel, A.; Mateos, D.; Bilbao, J.; Román, R. Sensitivity analysis of ratio between ultraviolet and total shortwave solar radiation to cloudiness, ozone, aerosols and precipitable water. Atmos. Res. 2011, 102, 136-144. [CrossRef]

42. Barnard, W.F.; Saxena, V.K.; Wenny, B.N.; DeLuisi, J.J. Daily surface UV exposure and its relationship to surface pollutant measurements. J. Air Waste Manag. 2003, 53, 237-245. [CrossRef]

43. Kaskaoutis, D.G.; Kambezidis, H.D. Investigation into the wavelength dependence of the aerosol optical depth in the Athens area. Q. J. R. Meteorol. Soc. 2006, 132, 2217-2234. [CrossRef]

44. Badarinath, K.V.S.; Kharol, S.K.; Kaskaoutis, D.G.; Kambezidis, H.D. Influence of atmospheric aerosols on solar spectral irradiance in an urban area. J. Atmos. Sol. Terr. Phys. 2007, 69, 589-599. [CrossRef]

45. Lee, S.; Hong, J.; Cho, Y.; Choi, M.; Kim, J.; Park, S.S.; Ahn, J.-Y.; Kim, S.-K.; Moon, K.-J.; Eck, T.F.; et al. Characteristics of Classified Aerosol Types in South Korea during the MAPS-Seoul Campaign. Aerosol. Air Qual. Res. 2018, 18, 2195-2206. [CrossRef]

(C) 2020 by the authors. Licensee MDPI, Basel, Switzerland. This article is an open access article distributed under the terms and conditions of the Creative Commons Attribution (CC BY) license (http://creativecommons.org/licenses/by/4.0/). 